\title{
ChemComm
}

\section{Enhancing optical absorption of metal-organic frameworks for improved visible light photocatalysis $\uparrow$}

\author{
Cite this: Chem. Commun., 2013 \\ 49, 10575 \\ Received 21st August 2013, \\ Accepted 22nd September 2013
}

DOI: $10.1039 / c 3 c c 46398 b$

\author{
Maxim A. Nasalevich, ${ }^{* a}$ Maarten G. Goesten, ${ }^{a}$ Tom J. Savenije, ${ }^{b}$ Freek Kapteijn ${ }^{a}$ \\ and Jorge Gascon*a
}

www.rsc.org/chemcomm

$\mathrm{NH}_{2}-\mathrm{MIL}-125(\mathrm{Ti})$ has been post-synthetically functionalized with dye-like molecular fragments. The new material (methyl red-MIL125(Ti)) exhibits improved light absorption over a wide range of the visible spectrum, and shows enhanced photocatalytic oxidation activity under visible light illumination. The consequences of functionalization and the bottlenecks in MOF photochemistry are studied in detail.

Metal-organic frameworks are crystalline porous solids possessing high surface areas and highly tuneable properties. This relatively new class of coordination compounds is being considered for application in different fields, such as heterogeneous catalysis, gas storage/separation and imaging. ${ }^{1-4}$ Among the wide variety of properties of interest, several MOFs exhibit very interesting optoelectronic features. For instance, recent synthetic achievements have delivered chemically robust MOFs displaying photocatalytic activity. In particular Ti- and Zr-based frameworks were successfully employed for a variety of photocatalytic transformations such as $\mathrm{CO}_{2}$ reduction, $\mathrm{H}_{2}$ evolution and oxidation of organic compounds. ${ }^{5-7}$ The first metal-organic framework constructed using titanium clusters and terephthalates was reported by Férey and co-workers. ${ }^{8}$ However, most MOFs based on terephthalate linkers exhibit optical absorption only in the UV-region, while undoubtedly the main challenge in photocatalysis lies in the complete utilization of the solar spectrum. In order to tackle this issue, several authors have demonstrated that by inclusion of amine moieties (using amino-terephthalic acid as a linker), it is possible to slightly extend light absorption of MIL-125(Ti) to the visible region. ${ }^{9-11}$ In this work we demonstrate that post-synthetic modification (PSM) ${ }^{12}$ of $\mathrm{NH}_{2}$-MIL-125(Ti) with antenna-like moieties can further extend visible light absorption,

\footnotetext{
${ }^{a}$ Catalysis Engineering, Department of Chemical Engineering, Delft University of Technology, Julianalaan 136, Delft, 2628 BL, The Netherlands E-mail:M.Nasalevich@tudelft.nl,J.Gascon@tudelft.nl; Fax: +31 1527 85006; Tel: +31152784851

${ }^{b}$ Optoelectronic Materials, Department of Chemical Engineering, Delft University of Technology, Julianalaan 136, Delft, 2628 BL, The Netherlands $\dagger$ Electronic supplementary information (ESI) available: Details of the synthesis, photocatalytic tests, X-ray diffraction data, $\mathrm{N}_{2}$ adsorption isotherms, DRIFTs, NMR and TRMC traces. See DOI: $10.1039 / \mathrm{c} 3 \mathrm{cc} 46398 \mathrm{~b}$
}

improving the photocatalytic performance of the framework under solar light illumination.

MIL-125(Ti) and $\mathrm{NH}_{2}$-MIL-125 were synthesized according to the method described elsewhere. ${ }^{13} \mathrm{NH}_{2}$-MIL-125 was post-synthetically functionalized following a diazotization reaction similar to that recently reported by Burrows and co-workers. ${ }^{14}$ At the first stage the amino groups of the framework reacted with nitrosonium ions, $\mathrm{NO}^{+}$, generated in situ by the $\mathrm{HCl}-\mathrm{NaNO}_{2}$ pair (ESI $\dagger$ ). The temperature of the reaction mixture was kept at $0{ }^{\circ} \mathrm{C}$ to avoid the denitrogenation of the diazonium salt. The second step is the reaction of $\mathrm{N} \equiv \mathrm{N}^{+}-\mathrm{MIL}-125(\mathrm{Ti})$ with diethylaniline, yielding a material referred to as methyl red-MIL-125(Ti) (MR-MIL-125(Ti)), in which the functional group resembles the well-known organic dye. During the synthesis we observed the suspension colour changing from yellow to almost white in the first step and then to dark orange in the second step (see video in ESI $\dagger$ ).

The XRD patterns of MIL-125(Ti) and as-synthesized $\mathrm{NH}_{2}$ MIL-125(Ti) correspond well to those reported previously and remain unchanged after the PSM (ESI + ), demonstrating the non-destructive transformation of the framework. The three materials were subjected to $\mathrm{N}_{2}$-physisorption analysis. As expected, pore volume decreases upon functionalization. DRIFT analysis demonstrates the disappearance of the amino-stretchings of $\mathrm{NH}_{2}$-MIL-125(Ti) ( 3519.5 and $3388.4 \mathrm{~cm}^{-1}$ ) after the modification (ESI $\dagger$ ). However the analysis of the fingerprint region did not provide a direct proof of the formation of the $\mathrm{N}=\mathrm{N}$ bond. In order to confirm the designed modification, MR-MIL-125(Ti) was digested in concentrated $\mathrm{KOH}$ and analysed by NMR spectroscopy. Fig. 1 displays the ${ }^{1} \mathrm{H}$ NMR spectrum of the digested methyl red-MIL-125(Ti). Resonances in the alkyl region undoubtedly demonstrate the successful functionalization. Quantitative analysis (ESI $\dagger$ ) suggests that $26 \%$ to $30 \%$ of the linkers were functionalised. The relatively low degree of functionalization is not surprising when considering the bulkiness of the MR moiety and the mechanism of the diazotization reaction, in which denitrogenation of the diazonium salt may take place. Because of these reasons, we speculate that the highest degree of functionalization will not be higher than $50 \%$, since successful functionalization of two adjacent linkers will be very unlikely. 


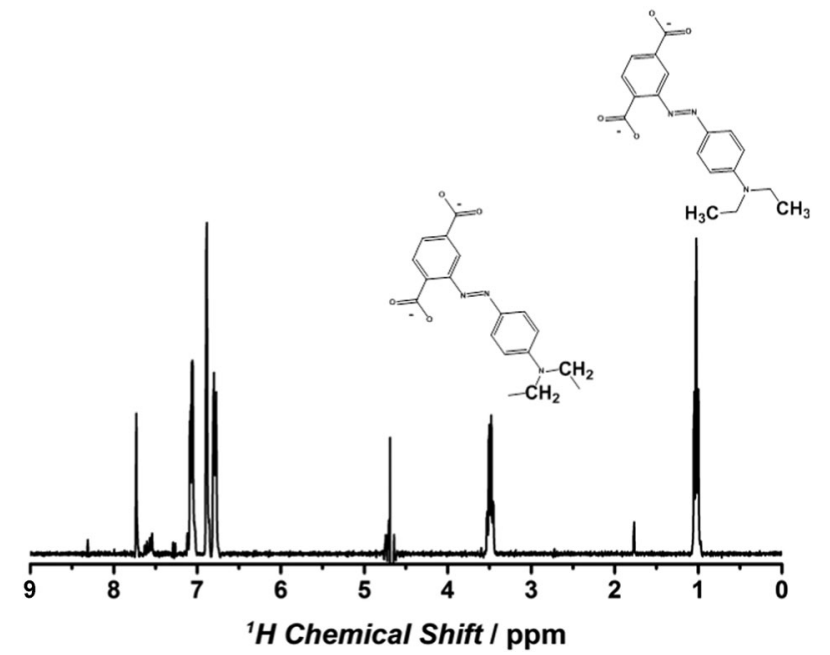

Fig. $1{ }^{1} \mathrm{H}$-NMR patterns of MR-MIL-125(Ti) digested in $\mathrm{KOH}$. The alkyl signals confirm the designed modification.

Optical absorption of the different materials was investigated using UV/Vis spectroscopy in diffuse reflectance mode. The main absorption bands of MIL-125(Ti) are located in the UV region. As expected, the presence of an electron donating substituent in the aromatic ring strongly affects the optical properties of the material. $\mathrm{NH}_{2}$-MIL-125(Ti) exhibits two absorption bands at 325 and $465 \mathrm{~nm}$ attributed to $\mathrm{ATA}^{2-} \mathrm{Ti}^{4+} \rightarrow \mathrm{ATA}^{-} \mathrm{Ti}^{3+}$ transition within the subunits of the framework. ${ }^{15-17}$ Once the material is modified, a clear red shift is observed with the absorption edge reaching almost $700 \mathrm{~nm}$. This significant visible light absorption enhancement can be associated with a higher level of conjugation of the aromatic system in the linker. The longer wavelength transitions of the MOF suggest that most of the modified linkers exist in the trans-form, since the cis- and trans-isomers of the analogous methyl red molecule embedded in rigid polymers absorb at $<400$ and $565 \mathrm{~nm}$ respectively. ${ }^{18}$ We attribute the preference of the trans-isomer to a more efficient packing in the micropores of the framework. The calculated band gap energies were found to be 2.46 and $1.93 \mathrm{eV}$ for $\mathrm{NH}_{2}$ - and MR-MIL-125(Ti) respectively $(\mathrm{ESI}+)$. As a result of the functionalization, MR-MIL125(Ti) absorbs $100 \%$ more light in the visible region than $\mathrm{NH}_{2}$ MIL-125(Ti) (ESI $\dagger$ ).

The photocatalytic activity of MR-MIL-125(Ti) was assessed in the selective oxidation of benzyl alcohol to benzaldehyde. Oxidation of alcohols to corresponding aldehydes is one of the most important reactions in organic synthesis. ${ }^{19}$ The aldehydes can then be used for the production of fragrances and flavours. ${ }^{20}$ The reactions were carried out in $\mathrm{CH}_{3} \mathrm{CN}$ taking into account the recent reports of the importance of the solvent for aerobic organic oxidation on $\mathrm{NH}_{2}$-UiO-66 by Wang et al. ${ }^{21}$ In our experiments a home-built photocatalytic reactor was employed illuminated from the top by a 150 Xe fiber light source filtered by a $400 \mathrm{~nm}$ cut-on filter (ESI $\dagger$ ) to ensure that only visible light is used.

The formation of benzaldehyde in the course of reaction is shown in Fig. 3. Blank experiments without illumination/ catalyst did not yield any quantifiable amount of benzaldehyde after 24 hours of reaction. Both $\mathrm{NH}_{2}$-MIL-125 and MR-MIL-125 are active under visible light illumination. However, even on a weight basis the functionalized MOF shows a higher activity. The reaction rates of benzaldehyde formation for $\mathrm{NH}_{2}$-MIL125(Ti) and MR-MIL-125(Ti) under the reaction conditions were found to be 77.6 and $86.7 \mathrm{nmol} \mathrm{g}^{-1} \mathrm{~min}^{-1}$ respectively (circa $40 \%$ improvement in the photocatalytic performance per atom of Ti present in the structure, see ESI $\dagger$ ). Although the activities found in this work are rather moderate, they are well in line with the values reported for visible light carbon dioxide reduction and hydrogen evolution using $\mathrm{NH}_{2}$-MIL-125(Ti). ${ }^{9,15}$ Benzaldehyde was the only product detected in the liquid phase suggesting that the selectivity of the process approaches $100 \%$. Additional experiments have shown that MR-MIL-125(Ti) can be easily recycled without any loss of activity (ESI $\dagger$ ). This is a clear advantage over bulk $\mathrm{TiO}_{2}$, where deactivation has been observed in similar photo-oxidation reactions due to irreversible product adsorption. ${ }^{22}$ The improvement of the photocatalytic activity in the case of MR-MIL-125(Ti) with respect to the parent framework is associated with the enhanced optical absorption of the solid due to the extended conjugation of the aromatic system of the ligand (see Fig. 2).

These results unambiguously demonstrate the possibility of tuning the optical absorption in MOFs, in line with our previous reports and with the most recent work by Walsh and co-workers. ${ }^{16,23}$ More importantly, we also demonstrate that improving light sensitivity only yields moderate gains in photocatalytic performance. In contrast to $\mathrm{TiO}_{2}$, the $\mathrm{HOMO} /$ valence band of the MIL-125 framework mainly consists of the $\pi$-orbitals of the aromatic ring of the linker. ${ }^{24}$ This explains the influence of ring substituents on the electronic excitation processes in the material. The difference between the $100 \%$ gain in light absorption and only $40 \%$ improvement in catalytic activity can be explained as follows: (i) optical absorption is not the unique factor contributing to the enhancement in activity, the difference in the adsorption properties should also be taken into account; (ii) not every photon within the absorption range possesses the necessary energy to drive the photocatalytic transformation. In order to gain more insight into these phenomena, we measured charge mobility in the parent framework by means of time-resolved microwave conductivity (TRMC). According to our results, MIL-125(Ti) shows a poor photoconductance (mobility $\sim 10^{-5} \mathrm{~cm}^{2} \mathrm{~V}^{-1} \mathrm{~s}^{-1}$ upon $340 \mathrm{~nm}$ illumination, ESI $\dagger$ ).

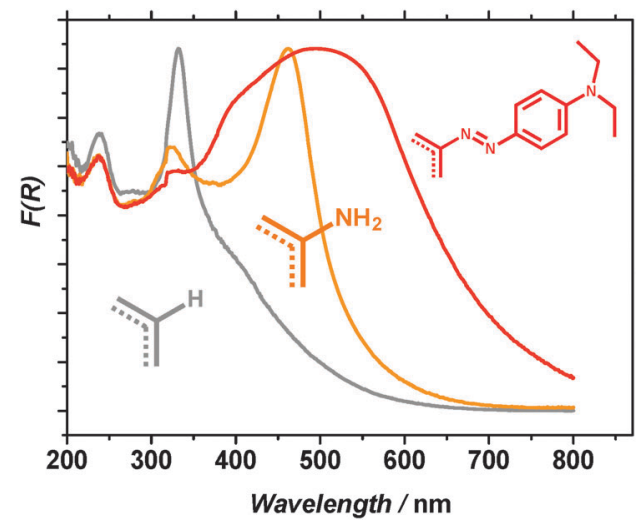

Fig. 2 Diffuse reflectance spectra of the materials investigated in this study: MIL-125(Ti) (grey), $\mathrm{NH}_{2}$-MIL-125(Ti) (orange) and MR-MIL-125(Ti) (red). 


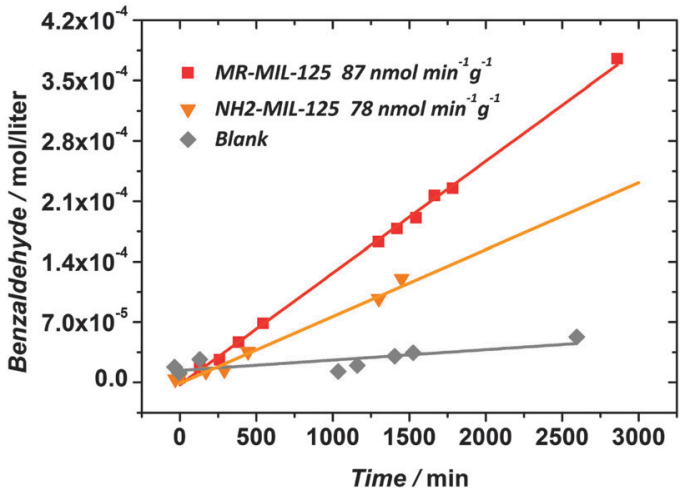

Fig. 3 Photocatalytic benzaldehyde evolution. No catalyst (grey), $\mathrm{NH}_{2}-\mathrm{MIL}-$ 125(Ti) (orange) and MR-MIL-125(Ti) (red). $200 \mu \mathrm{L}$ of benzyl alcohol/12 mL $\mathrm{CH}_{3} \mathrm{CN}, 150 \mathrm{~W}$ Xe lamp. $12 \mathrm{mg}$ of $\mathrm{NH}_{2}-\mathrm{MIL}-125$ (Ti) and $18 \mathrm{mg}$ of MR-MIL-125(Ti).

This conductance is significantly suppressed upon lowering the temperature to $153 \mathrm{~K}$, in clear contrast to pure $\mathrm{TiO}_{2}$, with mobilities in the range of $1 \mathrm{~cm}^{2} \mathrm{~V}^{-1} \mathrm{~s}^{-1}$ nearly independent of temperature. ${ }^{25,26}$ This difference suggests thermally activated hopping as the main mechanism for the charge transport due to the isolation of the $\mathrm{Ti}$ clusters by the organic linkers in the MOF. ${ }^{27}$ Indeed, such clusters are too far apart to fulfil the Mott transition conditions, being approximately 4 Bohr radii. $^{28,29}$ Moreover, in MIL-125(Ti), the distance between linkers is circa $7 \AA$, therefore, no efficient $\pi-\pi$ stacking is possible ${ }^{30}$ and there is hardly any orbital overlap, keeping the electrons preferentially in a localized state. This fact demonstrates that the MIL-125(Ti) series (and MOFs in general) should be seen as an array of selfassembled molecular catalysts rather than as classical semiconductors. Indeed, the optical absorption spectra depicted in Fig. 2 should be considered as sets of individual discrete absorption bands, and the HOMO-LUMO gap terminology should be used in order to describe the discrete characteristics of the lightinduced transitions in these coordination compounds. Therefore, the performance of MR-MIL-125(Ti) can be considered as contributions from two individual components: $\mathrm{NH}_{2}-\mathrm{MIL}$ 125(Ti) and MR-MIL-125(Ti). The ratio of the two as determined by the quantitative NMR analysis is $70: 30$. Thus $30 \%$ of the linkers that are functionalized are responsible for the $40 \%$ gain in activity.

In this communication, a straightforward PSM has been applied to improve the optical absorption of $\mathrm{NH}_{2}$-MIL-125(Ti). Post-synthetic functionalization of the organic linkers with the diazonium salt followed by the reaction with a nucleophilic species like diethylaniline yields the incorporation of dye-like moieties in the MOF scaffold. The resulting MR-MIL-125(Ti) displays a significant increase in light absorption as compared to the parent MOF. When applied in the selective photooxidation of benzyl alcohol under visible light illumination, the MR-MIL-125(Ti) framework displays an enhanced photocatalytic performance. This improvement is associated with the improved optical absorption of the catalyst.

In order to rationalize the catalytic results, photoconductance of MIL-125(Ti) has been explored using time-resolved microwave conductivity. Temperature-dependent signals of $\sim 10^{-5} \mathrm{~cm}^{2} \mathrm{~V}^{-1} \mathrm{~s}^{-1}$ were detected. This low conductivity clearly demonstrates that the MIL-125(Ti) series should be seen as an array of self-assembled molecular catalysts rather than as classical semiconductors.

We would like to gratefully acknowledge the Dutch National Research School Combination Catalysis Controlled by Chemical Design (NRSC-Catalysis) for funding this research. We thank Maria C. Fravventura for assistance with the TRMC experiments.

\section{Notes and references}

1 J. Della Rocca, D. Liu and W. Lin, Acc. Chem. Res., 2011, 44, 957-968. 2 E. V. Ramos-Fernandez, C. Pieters, B. van der Linden, J. Juan-Alcañiz, P. Serra-Crespo, M. W. G. M. Verhoeven, H. Niemantsverdriet, J. Gascon and F. Kapteijn, J. Catal., 2012, 289, 42-52.

3 J. Juan-Alcaniz, J. Gascon and F. Kapteijn, J. Mater. Chem., 2012, 22, 10102-10118.

4 S. Couck, E. Gobechiya, C. E. A. Kirschhock, P. Serra-Crespo, J. JuanAlcañiz, A. Martinez Joaristi, E. Stavitski, J. Gascon, F. Kapteijn, G. V. Baron and J. F. M. Denayer, ChemSusChem, 2012, 5, 740-750.

5 J. L. Wang, C. Wang and W. Lin, ACS Catal., 2012, 2, 2630-2640.

6 C. G. Silva, I. Luz, F. X. Llabrés I Xamena, A. Corma and H. García, Chem.-Eur. J., 2010, 16, 11133-11138.

7 C. Wang, Z. Xie, K. E. Dekrafft and W. Lin, J. Am. Chem. Soc., 2011, 133, 13445-13454.

8 M. Dan-Hardi, C. Serre, T. Frot, L. Rozes, G. Maurin, C. Sanchez and G. Férey, J. Am. Chem. Soc., 2009, 131, 10857-10859.

9 Y. Horiuchi, T. Toyao, M. Saito, K. Mochizuki, M. Iwata, H. Higashimura, M. Anpo and M. Matsuoka, J. Phys. Chem. C, 2012, 116, 20848-20853.

10 M. De Miguel, F. Ragon, T. Devic, C. Serre, P. Horcajada and H. García, ChemPhysChem, 2012, 13, 3651-3654.

11 M. Kim and S. M. Cohen, CrystEngComm, 2012, 14, 4096-4104.

12 S. M. Cohen, Chem. Rev., 2011, 112, 970-1000.

13 M. A. Moreira, J. C. Santos, A. F. P. Ferreira, J. M. Loureiro, F. Ragon, P. Horcajada, P. G. Yot, C. Serre and A. E. Rodrigues, Microporous Mesoporous Mater., 2012, 158, 229-234.

14 D. Jiang, L. L. Keenan, A. D. Burrows and K. J. Edler, Chem. Commun., 2012, 48, 12053-12055.

15 Y. Fu, D. Sun, Y. Chen, R. Huang, Z. Ding, X. Fu and Z. Li, Angew. Chem., Int. Ed., 2012, 51, 3364-3367.

16 J. Gascon, M. D. Hernández-Alonso, A. R. Almeida, G. P. van Klink, F. Kapteijn and G. Mul, ChemSusChem, 2008, 1, 981-983.

17 H. Khajavi, J. Gascon, J. M. Schins, L. D. A. Siebbeles and F. Kapteijn, J. Phys. Chem. C, 2011, 115, 12487-12493.

18 G. J. Lee, D. Kim and M. Lee, Appl. Opt., 1995, 34, 138-143.

19 S. V. Ley and A. Madin, in Comprehensive Organic Synthesis, ed. M. T. Barry and F. Ian, Pergamon, Oxford, 1991, pp. 251-289.

20 S. Higashimoto, N. Kitao, N. Yoshida, T. Sakura, M. Azuma, H. Ohue and Y. Sakata, J. Catal., 2009, 266, 279-285.

21 J. Long, S. Wang, Z. Ding, S. Wang, Y. Zhou, L. Huang and X. Wang, Chem. Commun., 2012, 48, 11656-11658.

22 A. R. Almeida, M. Calatayud, F. Tielens, J. A. Moulijn and G. Mul, J. Phys. Chem. C, 2011, 115, 14164-14172.

23 C. H. Hendon, D. Tiana, M. Fontecave, C. Sanchez, L. D'arras, C. Sassoye, L. Rozes, C. Mellot-Draznieks and A. Walsh, J. Am. Chem. Soc., 2013, 135, 10942-10945, DOI: 10.1021/ja405350u.

24 A. Walsh and C. R. A. Catlow, ChemPhysChem, 2010, 11, 2341-2344.

25 M. C. Fravventura, D. Deligiannis, J. M. Schins, L. D. A. Siebbeles and T. J. Savenije, J. Phys. Chem. C, 2013, 117, 8032-8040.

26 T. J. Savenije, A. Huijser, M. J. W. Vermeulen and R. Katoh, Chem. Phys. Lett., 2008, 461, 93-96.

27 R. A. Marcus, J. Chem. Phys., 1956, 24, 966-978.

28 Heterogeneous photocatalysis, ed. M. Schiavello, Wiley, Chichester, UK, 1997.

29 N. F. Mott, Can. J. Phys., 1956, 34, 1356-1368.

30 V. Barone, M. Casarin, D. Forrer, M. Pavone, M. Sambi and A. Vittadini, J. Comput. Chem., 2009, 30, 934-939. 